This is the peer reviewed version of the following article: Branigan, H. E. and Donaldson, D. I. (2019), Learning from learning logs: A case study of metacognition in the primary school classroom. Br Educ Res J, 45: 791-820, which has been published in final form at https://doi.org/10.1002/berj.3526. This article may be used for non-commercial purposes in accordance with Wiley Terms and Conditions for self-archiving.

\title{
Learning from learning logs: A case study of metacognition in the primary school classroom.
}

\author{
Heather E. Branigan ${ }^{\mathrm{a}}$ and David I. Donaldson ${ }^{\mathrm{b}}$
}

\begin{abstract}
${ }^{a}$ Ms. Heather E Branigan, Division of Psychology, Faculty of Natural Sciences, University of Stirling, Stirling, FK9 4LA. Email: h.e.branigan@stir.ac.uk. Phone Number: +44(0)7875369126

${ }^{\mathrm{b}}$ Professor David I. Donaldson, Division of Psychology, Faculty of Natural Sciences, University of Stirling, Stirling, FK9 4LA. Email: d.i.donaldson@stir.ac.uk. Phone Number: $+44(0) 1786467657$.
\end{abstract}

Note:

Correspondence concerning this article should be addressed to Heather E. Branigan, Division of Psychology, Faculty of Natural Sciences, University of Stirling, Stirling, FK9 4LA. Email: h.e.branigan@stir.ac.uk. Phone Number: +44(0)7875 369126

Acknowledgements: Many thanks to all pupils and staff who contributed and facilitated this research project. Thank you also, to Dr. Sandra Eady and Dr. Christine Stephen, who assisted with the design of the research project.

Compliance with Ethical Standards: The present research received full ethical approval from the University of Stirling Psychology Ethics Committee and was granted approval by Education and Child Services at the Local Authority in which the research took place. All participating teachers and student guardians provided informed consent through established research communication procedures in each research site (school).

Funding: This research is supported by a PhD scholarship awarded to Heather E. Branigan, from the Carnegie Trust for the Universities of Scotland.

Conflict of Interest: The authors declare that they have no conflict of interest. 


\section{Learning from learning logs: A case study of metacognition in the primary school classroom.}

Structured Thinking Activities (STAs) are pedagogical tools used to support metacognition in classrooms. Despite their popularity, little is known about how pupils use STAs as platforms to think about and manage their own thinking (i.e., as metacognitive tools). This case study investigated pupils' use of STAs in relation to metacognition throughout a school year. We focus on two eight-year-old pupils, Amy and Laura, as they completed two specific STAs through weekly class meets and termly achievement logs. Data were triangulated through participant observation, qualitative interviews and analysis of written texts. We found clear differences between Laura and Amy's written STAs, however observation and interviews revealed that engagement with STAs was similar beyond that suggested by written evidence alone. Whereas Amy used easily-spelt 'stock' responses, Laura used 'bare minimum' responses to meet teacher expectations. As such, neither Amy nor Laura used STAs as metacognitive tools, however in negotiating STAs, both exhibited strategic regulatory skills indicative of metacognition. Whilst our findings highlight that pupils may still be developing explicit metacognitive knowledge necessary to take full advantage of STAs, we highlight the clear value of persistent approaches to use STAs as tools to support developing metacognition, particularly in association with teacher-pupil interactions.

Keywords: metacognition; learning; learning logs; classroom; thinking; case study

\section{Introduction}

Several approaches are used in classrooms to encourage pupils to develop awareness and control of their own thinking and learning. Such approaches include pedagogical practices embedded throughout everyday classroom activities as well as more structured approaches, all under broad headings of thinking skills and learning to learn (e.g., Baumfield, 2006; Higgins et al., 2007). The focus in the present study is on exploring specific Structured Thinking Activities (STA) that are conducted routinely in primary school classrooms to promote pupils' increasing awareness of their own thinking and learning. That is, pedagogical approaches surrounding learning portfolios, or learning logs.

In the present study we use the term 'Structured Thinking Activities' (STAs) to refer to one specific pedagogical tool, often described using various terms such as learning logs, learning portfolios, thinking protocols or personal planning diaries. Such STAs are commonly used in classrooms throughout the UK and beyond. It is widely believed that through encouraging planning and reflection, STAs provide a platform for pupils to think about and manage their own thinking (i.e. engage in metacognition). Despite their popularity within the educational setting, little is known about how pupils engage with STAs, and (ultimately) their relationship to pupils' developing metacognition. The present study draws on ethnographic methods to explore the experiences of two primary four pupils in a Scottish primary school as they are 
introduced to weekly STAs. This case study investigates Laura and Amy's experiences of learning logs as well as learning chats between pupil and teacher, as these STAs are newly introduced into the classroom and progress throughout the course of a school year. We seek to provide thick descriptions, locating action 'within context' to establish deeper meaning (Geertz, 1973). In doing so, we explore the ways pupils negotiate the use of STAs in the rich social environment of the classroom.

\section{Metacognition}

Metacognition, broadly defined, relates to the capacity to think about and manage one's own cognition (or to 'think about thinking'). It is widely agreed that the term metacognition encapsulates two main components of metacognitive knowledge and metacognitive regulation (Flavell, 1979; Schraw \& Moshman, 1995; Efklides, 2006). More specifically, metacognitive knowledge describes the 'what, when and why' of cognition (Schraw \& Moshman, 1995), reflecting the capacity for individuals to think about themselves, tasks and strategies (Flavell, 1979), including one's strengths and weaknesses (Schraw, 1994). In contrast, metacognitive regulation describes the processes through which individuals control their own cognition, through planning, monitoring and evaluating (Schraw \& Moshman, 1995; Veenman \& Spaans, 1995; Efklides, 2006). Within the classroom, it is beneficial to consider metacognition in relation to Self-Regulated Learning (SRL), emphasising the way individuals think about and manage their own thinking and learning in the applied context. Briefly, Zimmerman's (1990) theory of SRL comprises three components: learning strategies (behaviour), responsiveness to self-orientated feedback about learning (metacognition), and motivational processes (motivation). Whilst debate exists as to the exact relationship between SRL and metacognition, it is broadly agreed that metacognition comprises one key aspect of wider self-regulation (Veenman, Van Hout-Wolters \& Afflerbach, 2006).

Several meta-analyses have highlighted the value of metacognitive interventions within the primary school years (Hattie, Biggs \& Purdie, 1996; Dignath, Buettner \& Langfeldt, 2008; Higgins et al., 2004, 2005) and metacognition has been identified as one of the most valuable and cost-effective approaches amongst current educational approaches (Higgins et al., 2016). Metacognition has particularly been identified as valuable for improving academic performance of pupils identified as having lower cognitive abilities (Swanson, 1990; Zohar \& Peled, 2008; Higgins et al., 2004).

Much of our understanding about metacognition has been based upon insights produced from traditional cognitive experiments (including the influential theories of John Flavell and Gregory Schraw). Indeed, metacognition is frequently studied through experimental paradigms in which comparisons are made between estimated and actual performance in carefully controlled tasks. For example, metacognition is often measured using Judgement of Learning paradigms, asking individuals to memorise content (such as strings of information or word pairs) and predict the likelihood of recalling at a future point. Such estimates have been used to demonstrate that metacognitive processes are distinct from cognitive processes per se (cf. Skavhaug, Wilding \& Donaldson, 2010) and provide an estimate of an individual's metacognitive accuracy (e.g. Flavell, Friedrichs \& Hoyt, 1970; Destan, Hembacker, Ghetti \& Roebers, 2014). 
From this cognitive psychological perspective, it was traditionally believed that metacognition did not develop until the middle primary school years, with children below this age having limited capacity for metacognition (Armbruster, Echols \& Brown, 1982; Bartsch, Horvath \& Estes, 2003; Veenman, Wilhelm \& Beishuizen, 2004). More recently, however, classroom-based research has used more sensitive methodologies to investigate the metacognitive abilities with much younger pupils. For example, classroom-based observational tools have identified indictors of metacognitive knowledge and regulation from the ages of three to four years old (Whitebread et al., 2009; Robson, 2016a, 2016b). In addition, visual tools have been developed that elicit children's understanding of their own thinking and learning through concept maps (Ritchhart, Turner \& Hadar, 2009) and Pupil Views Templates (PVTs: see Wall, 2008; Wall et al., 2012). In PVTs, a cartoon scenario is presented, with empty thought and speech bubbles for pupils to document their thinking in a given situation (Wall \& Higgins, 2006; Wall et al., 2012). The inclusion of both thought and speech bubbles allow for exploration of the internal thought process and the external processes respectively. As such, PVTs can be seen as powerful tools in the metacognitive as well as cognitive domain (Wall \& Higgins, 2006). Research using PVTs to explore metacognition in the classroom has revealed that children do in fact demonstrate metacognitive knowledge and regulation from the early years, between 4 and 5 years old (Wall, 2008).

Such classroom-based research methods demonstrate a key consideration in the field of metacognition research. That is, the degree to which assessments of children's metacognitive capacities are dependent upon the measure employed. Desoete (2008) investigated metacognitive skills using multiple methods, including teacher ratings, as well as prospective and retrospective ratings from children themselves. Comparing measures, Desoete (2008) found that whilst there were general correlations between measures, the understanding of metacognition was heavily related to the measure employed, prompting the conclusion that "how you test is what you get" (p204). Furthermore, in a recent systematic review, Gascoine and colleagues (2017) found that there were clear age differences in the methods used to gauge metacognition throughout the school years, with the most common approach identified as self-reports. Interestingly, self-reports were employed exclusively to measure metacognition in children over seven years of age, and observational approaches being adopted for younger pupils (Gascoine, Higgins \& Wall, 2017). Such a finding is reflective of the relative strengths and weaknesses of research approaches. That is, whilst self-report inventories are a very common approach to the study of metacognition, a clear limitation is their reliance upon reading and verbal processing abilities (Misailidi, 2010; Whitebread \& Basillo, 2012). By contrast, whilst observing the internal process of metacognition is inherently problematic, the value of using observations in research with young children is intuitively clear, given the decreased demands on young children during direct observation of behaviour (Perry et al., 2002).

The present study seeks to use observational approaches to investigate metacognition by exploring the pedagogical tools used in everyday classrooms to facilitate metacognition. Indeed, despite the stated value of metacognitive approaches within the classroom, there exists a large gap in the research literature. That is, whilst approaches often seek to change teacher practice by developing structured interventions that are assessed for their effectiveness, research generally focuses less upon the ways that teachers encourage pupils to think about and manage their thinking throughout their 
everyday classroom lessons (i.e., in the absence of a specific intervention). We believe that such an approach will allow us to begin to explore the 'impact' of research within the classroom, and the ways that research evidence and metacognitive practices relate and/or differ. This study investigates one way that teachers describe encouraging pupils to think about and manage their own thinking; through Structured Thinking Activities.

\section{Structured Thinking Activities}

A number of different pedagogical tools are used within classrooms to develop pupils' thinking skills. For example, in their review of thinking skills programmes throughout formal schooling, Higgins et al. (2004) identified seventeen specific programmes used in classrooms. Similarly, a detailed review of professional enquiry approaches used in English schools identified a diverse range of approaches to encourage thinking skills under the ' 5 Rs' of Resilience, Readiness, Reflectiveness, Resourcefulness and Remembering (Higgins et al., 2007). Prominent approaches to the development of thinking skills used in schools include Cognitive Acceleration through Science Education (Adey \& Shayer 1990; Adey, Shayer \& Yates, 1995), Instrumental Enrichment (Feurstein, Hoffman \& Miller, 1980) and Philosophy for Children (Lipman, Sharp \& Oscanyan, 1980; Fisher, 2007). Importantly, however, in addition to these kinds of structured activities, thinking skills are also embedded (or 'infused') throughout everyday lessons - though discussion, questioning and modelling thinking (Baumfield, 2006; Wall \& Hall, 2016).

One main way that teachers in Scottish primary schools describe encouraging pupils to think about their own thinking (i.e., to encourage metacognition) is through tools such as learning logs or planning books. These structured thinking activities have been described using several different terms, including learning logs, learning diaries, personal development logs and achievement books (Moon, 2002), with Learning Logs and E-Portfolios being identified in the review of thinking skills approaches by Higgins et al. (2007). In the present study, we use the term 'structured thinking activities' (hereafter STAs) to refer to these specific activities used within the classroom to provide a structured platform for pupils to think about their own thinking. We draw a contrast between STAs and everyday classroom activities (such as numeracy tasks or literacy tasks) that may include an aspect of thinking about thinking (for example through 'infusion'), but where thinking about thinking itself is not the sole goal of the task. STAs contain several diverse prospective and retrospective activities, such as creating weekly or termly targets, evaluating pieces of work (of the self or a peer) and reflecting on targets for the week, term or year.

\section{Structured Thinking Activities and metacognition}

The connection between STAs and metacognition is intuitively apparent. Indeed, a relationship is implicit in descriptions of journals that emphasise independence (Moon, 2002). Barclay (1996) describes a STA as;

a flexible method which recognizes that learning is a personal, individual process. By planning development activities, it incorporates elements of active self-directed learning, and reinforces individual responsibility in development (p30) 
Here, the connections between metacognition and STAs are clear; activities provide not only a platform upon which to reflect on learning (i.e. develop metacognitive knowledge), but also to control one's own cognition through planning, monitoring and reflecting (i.e. engage with metacognitive regulation).

Despite their popularity and intuitive relationship to metacognition, relatively few research studies have investigated the ways that teachers and pupils use STAs, and how these activities relate to the development of metacognition (Paris \& Paris, 2001). As a result, it is currently unclear what processes underlie the purported 'benefit'. Where studies do exist, these predominantly measure the 'effects' of specific STAs, often in high school or Higher Education contexts. For example, Audet, Hickman and Dobrynina (1996) found that learning logs supported high school pupils' understanding of scientific concepts. Similarly, Smith, Rock and Smith (2007) found that asking metacognitive questions in learning logs improved high school pupils' history grades more than asking purely cognitive questions. In higher education contexts, McCrindle and Christensen (1995) found that students who documented their learning in journals had increased metacognition, cognitive strategy use and science performance (compared to controls, who completed a scientific report). Also in higher education, Nückles, Hübner and Renkel (2009) found that cognitive performance was improved when students were given cognitive and metacognitive prompts in learning journals (compared to no prompts).

In a more recent study, Mallozzi and Heilbronner (2013) investigated the impact of different content delivered through interactive pupil notebooks (ISNs) in science classes, comparing between a) the delivery of metacognitive instruction plus teacher feedback, b) metacognitive instruction alone, and c) no ISN at all. In the metacognitive instruction that was provided to pupils in conditions a) and b), pupils were supported to make interpretations, reflect on their work, and make connections between subject areas. Results of the study indicated that pupils perceived the ISNs as useful for improving learning in science, and the use of ISNs did indeed improve pupils' performance compared to no ISN use. Pupil performance was improved in both conditions that included metacognitive instruction, regardless of whether metacognitive instruction was provided alone, or in addition to written feedback from teachers. Some evidence does, therefore, suggest beneficial effects of STAs upon pupils' academic performance - particularly when STAs explicitly encourage metacognition. Some evidence does, therefore, suggest beneficial effects of STAs upon pupils' academic performance - particularly when STAs explicitly encourage metacognition.

Despite some evidence suggesting their educational benefits, we find that the diversity of approaches to STAs and the general lack of research about their use in the primary school years is striking. Clearly, we cannot assume that the mere presence of these STAs will influence pupils' reflection, metacognition or (ultimately) learning. Although some research has identified a relationship between STA use and performance, little is known about the content of STAs, and most importantly, the ways that pupils think about and manage their own thinking whilst completing STAs. For example, the finding that low-achieving pupils benefit more from metacognitive interventions leads us to question whether pupils identified as traditionally 'lowachieving' will differ in their engagement with STAs compared to their 'highachieving' peers. In sum, given the popularity of STAs in primary schools, further 
research is clearly needed to investigate their use in the primary school setting, and the way they can facilitate pupils' developing metacognition.

\section{The Present Study}

The present study sought to provide deep contextual insight into the ways that STAs are used within the classroom, and what they can reveal about pupils' developing metacognition. More specifically, we aimed to explore the ways that pupils think about and manage their own thinking using STAs. We aimed to explore individual pupils' experiences of STAs, and any similarities and differences that can be observed. We were guided by the following research questions;

- What do STAs reveal about the metacognitive process? That is, in what ways do pupils think about and manage their own thinking as they complete STAs?

- What similarities and differences in STA use exist between pupils identified by the teacher as differing in terms of traditional academic skills?

\section{Methodology}

In the present study, we adopted a qualitative approach to consider the numerous influences upon the ways pupils think about their own thinking and express their thinking in the classroom. We present a case study of the use of STAs within a 'real life' classroom context, a qualitative approach that we identified as appropriate given our goal of understanding the role of STAs in relation to metacognition (Robson, 2011). The present study draws specifically on ethnographic methods, seeking to investigate "first-hand what people do and say in particular contexts" (Hammersley, 2006, p4). We sought to create "thick descriptions" (Geertz, 1973), and to describe STAs from the perspectives of participants from inside (Robson, 2011, p143).

It is our perspective that our findings will serve as a reflective lens to both researchers and practitioners "who because of their own interpretive and sense-making capacities, will derive their own unique meanings or 'readings' of the text" (Altheide \& Johnson, $1998 \mathrm{p} 286$ ). As time is critical for interpretation of events or behaviours in the classroom, it was important for us to collect data throughout the duration of one school year, using intermittent periods of data collection that became more focussed over time (as termed a 'selective intermittent time mode' by Jeffrey \& Troman, 2004). Data collection took place throughout the 2016-17 academic year.

Our research was granted full ethical approval by the Psychology Ethics Committee at the researchers' host institution and was granted approval by the Education and Children's Services Directorate at the Local Authority level. All participants were informed of the research and invited to raise questions or withdraw participation at any time and for any reason. Full informed consented was obtained by the class teacher, and in line with the research procedures of the school, all pupil guardians were provided with an information form, and invited to contact the school is they refused consent for their children to take part. Throughout this paper, all names of participants and places are pseudonyms and all identifying characteristics have been removed or changed. 
The main source of data collection in the present study was participant observation, in that the researcher was a member of the setting in which they collected data. More specifically, the researcher adopted a 'participant as observer' stance. In this sense, it was clear to all pupils and the teacher from the outset that the researcher was participating in the class as an observer (Robson, 2011). To provide a deep exploration of the differing experiences of pupils as they interacted with STAs, we followed two specific pupils in the class (as outlined in more detail below). Throughout observations, the researcher took part in some of the activities as appropriate, for example through discussing with pupils, assisting when required, or sometimes being part of a small group as pupils worked on STAs. This position was appropriate as maintaining a solely 'outsider observer' status would have been an unnatural position for a visitor throughout a school year to take, and involvement helped to develop trust within the setting (Bryman, 2012). In addition, involvement with classroom activities was a more natural route to discuss the activities with pupils; "as well as observing through participating in activities, the observer can ask members to explain various aspects of what is going on" (Robson, 2011, p322).

As is key for case study research, the present study sought to gather data from several sources (Yin, 2009). We saw the collection of multiple sources of data as fundamental; to enhance rigour, to immerse ourselves in the research site and to provide a contextualised understanding of the experience of STAs in the classroom (Hammersley, 2006; Robson, 2011). In addition to participant observation, we also investigated STAs through open-interviews with participants (pupils and the teacher) and through analysis of texts produced by pupils (such as excerpts of written STAs). Open, or unstructured interviews, allowed more rich and contextual investigation of pupils' own experiences as they completed STAs (Fontana \& Frey, 1998). The inclusion of written texts as a source of data (Bryman, 2012) further allowed us to explore the interaction between the products of STAs with the experiences of pupils throughout the process of completing activities.

Data were collected primarily through field notes taken by the first author, supported by audio recordings of discussions between pupils and researcher whilst conducting STAs, where possible. When creating field notes, the researcher sought to document events in real time through detailed running records (Perry, 1998). Field notes were reviewed at the end of each data collection episode, at which point the researcher elaborated upon field notes and transcribed any audio-recorded excerpts. The focus in the present study was as far as possible to document instances that 'capture the essence' of meaningful events (Walford, 2009). As is common in research using ethnographic methods, themes began to emerge throughout the process of data collection. As such, data collection and analysis took place concurrently (Jeffrey, 2008).

Following each episode of data collection, the field researcher adopted open coding of field notes, with photographs of documents providing additional 'illuminative' evidence (Craft, Cremin, Hay \& Clack, 2014, p21). Over the course of data collection, emerging themes were highlighted in field notes. An inductive approach was used, allowing themes to emerge from the 'ground up'. Whilst clearly being guided by our understanding of metacognition from the theoretical overview outlined above, we sought not only to test existing metacognition theory in relation to STAs, but also to build understanding that was grounded in (and resembles closely), the specific context investigated (Strauss \& Corbin, 1991; Charmaz, 2000). This iterative and flexible approach allowed emerging themes to be explored in greater depth as data collection 
progressed; for example, through discussing emerging themes from observations in conversation with the teacher or pupils (Robson, 2011). In addition, research literature was read and used throughout data collection in an iterative fashion (Strauss \& Corbin, 1991), as reflected in the findings section of this study. Emerging themes were continuously interrogated by the entire research team; analytic rigour was achieved through discussion and debate within the research team, in relation to wider literature, until consensus was reached.

\section{Structured Thinking Activities at Forestview Primary School}

Data collection took place within one primary four classroom in Forestview Primary School in central Scotland. Opened in the late 1800s, Forestview Primary School is a non-denominational Local Authority school comprised of 14 classrooms. The school is situated in an area identified as in the most deprived quintile in Scotland (as in, falling within the $20 \%$ most deprived postcodes within Scotland) by the Scottish Index of Multiple Deprivation (or SIMD) ${ }^{1}$. Within the local and national policy context, there is an increasing focus upon approaches relating to thinking skills in the classroom (Scottish Government, 2009), reflected by the Curriculum for Excellence's four capacities; successful learners, confident individuals, responsible citizens, effective contributors (Education Scotland, 2018).

At the time of data collection, there was an explicit focus upon approaches to encourage learners to think about their own thinking and learning within Forestview Primary School. This was described in the inside of the pupils' Achievement log;

At Forestview Primary School we aim to [...] actively involve the children in planning and assessment to ensure they have a well-developed sense of ownership of their learning and help one another [...] Children should be able to articulate clearly, according to their age and stage of development, their strengths as a learner and what they need to do to improve (excerpt from cover page in the primary 4 Achievement log, bold in original)

The commitment of Forestview Primary School to developing pupils' understanding about their own thinking and learning was also reflected in the school's enthusiasm about taking part in research and in encouraging the sharing of experiences between research and practice.

The present research follows a primary four class taught by the class teacher, Ms. Abbot, who indicated interest in taking part in the research following discussion about the research between the researcher and Head Teacher of Forestview Primary School. At the beginning of the study, Ms. Abbott had been a teacher for four years. In discussing her interest in STAs, Ms. Abbot described to the researcher that she had

${ }^{1}$ The SIMD is the measure of deprivation used by the Scottish Government to identify schools in areas of Scotland with the highest concentration of individuals facing deprivation. The estimates for Forestview Primary School are from the latest statistics, 2013. For further information on SIMD, please see http://www.gov.scot/Topics/Statistics/SIMD 
received some training as part of her initial teacher training that she saw as related to the research project;

I didn't get any input about metacognition when I was at Uni, nothing about children thinking about their learning. It was only when I came here and the whole Carol Dweck, growth mindset thing came in and I was quite interested in it. I was hardly at the same level as yourself, but I did a bit of psychology as part of my degree, so I find it quite interesting (discussion between Ms. Abbot and researcher)

Ms. Abbot described early in data collection that approaches to visible learning and growth mindsets were part of the school's improvement planning, "our school improvement plan is all about making learning visible and getting children involved in their learning, so this is all very related" (discussion between Ms. Abbot and researcher).

In the primary four class at Forestview, STAs were delivered through two main routes: (1) weekly 'class meets' that included both 'learning chats' between Ms. Abbot and the whole class, and short written activities in the form of sentences completed in individual 'learning logs', and (2) termly STAs that involved pupils planning and reflecting on thinking and learning through activities presented in an 'achievement log' that was sent home periodically to parents. The following sections provide descriptions of each STA.

Class Meets - Data collection began as Ms. Abbot introduced STAs as part of weekly 'class meets'. Class meets were typically conducted once a week, on Friday afternoons (beginning at around 2.30pm) and followed 'star time' - leisure time to reward pupils who had showed good behaviour throughout the week. In class meets, Ms. Abbot gathered pupils together as a whole class at the front of the classroom to discuss their learning from throughout the week. Discussions were often guided by sentences that Ms. Abbot prepared on the board to guide discussion, such as "this week I have been showing strength in...". Following the learning chat, pupils were often asked to complete sentences in their learning logs; small booklets described by the Ms. Abbot as;

about what's happened in the week, and what you can do next week to keep improving. Because there's not any point in not improving anymore, we need to keep improving, and we need to think of ways that we can keep improving (observed learning chat)

Ms. Abbot intended for class meets to form a routine for students, "I know that if I make it like, you get back from star time, you do your sentences, and then you can relax, then they won't mind doing it, it will be more of a routine" (discussion between Ms. Abbot and researcher).

Achievement Logs - At the beginning of data collection, achievement logs were a more established practice within the classroom and were completed in all classes throughout the school. Achievement logs were typically conducted at least twice a term during the research study. More specifically, achievement logs were used as a tool to encourage pupils to create targets at the beginning of each term, and to reflect on targets at the end of each school term (see Figure 1 for an example). In addition, achievement logs 
displayed excerpts of everyday learning activities, and were periodically taken home to share with guardians.

[Figure 1 about here]

\section{Laura and Amy}

The present study focused upon two pupils within the primary four class in Forestview Primary School. Laura and Amy were identified by Ms. Abbot as pupils who were similar in some regards, but different in relation to academic performance;

they are very similar in personalities. [Amy] is one of the poorest in the class and [Laura is] probably one of the most able. So, they are poles apart but at the same time it is quite good to see the range (discussion between Ms. Abbot and researcher)

Ms. Abbot also described the differences between Amy and Laura in terms of thinking about thinking;

Laura is always on about her learning and talking about the ways that she learns, whereas Amy is [...] one of the ones who was like "just give me the instruction and I'll do it". She was kind of like "so what are you actually asking me to do?" (discussion between Ms. Abbot and researcher)

Focusing on Laura and Amy, therefore, allowed us to address our second research question by investigating similarities and differences between pupils identified as differing in traditional academic skills.

\section{Findings}

In the following sections, we describe data relating to Laura and Amy's use of STAs throughout one academic year. We present findings and our interpretations together, before bringing together findings in a general discussion. Throughout findings, observed non-verbal behaviour is indicated by squared parenthesis. Our results firstly focus on key themes that arose from analysis focusing on Laura's engagement with STAs, followed by Amy's engagement with STAs, before discussing similarities and differences between pupils.

\section{Laura's experience of structured thinking activities}

\section{Discussions of learning}

From the beginning of the school year, Laura appeared to be comfortable discussing her own learning. For example, when discussing goals in a learning chat, Laura provided one of the most detailed and specific goals in relation to the rest of the class. Whereas others in the class described goals such as 'doing the pummel' or 'more maths', Laura stated, 'mine is to speak at least three sentences in fluent French' (observed learning chat). Laura also articulated her beliefs about how she learns best; "I work best when I 
have at least one person to work with, or when we're doing maths activities, and when people around me aren't being silly" (observed learning chat). Here, Laura again provided more depth to her response than most of the class, who tended to repeat the teacher's suggestions such as "when it's quiet" or "when I'm working by myself" (observed learning chat). In discussion with the researcher whilst completing a learning $\log$, Laura justified her responses about her assessments of the difficulties of tasks;

Researcher: Is reading a tricky thing to do, or...?

Laura: It's um, an easy thing, because I can understand nearly all the words. Researcher: And what do you do when there are words that you don't understand?

Laura: I just have a go at them

Researcher: Have a go? That's good. And what about something that you found tricky this week?

Laura: Maths. Because, I'm just too tired, and I just can't be bothered Researcher: Oh no, you can't be bothered! What do you do when you have a tricky thing to do in maths though?

Laura: I just do um, what I've been taught to do, and just see how it goes. Researcher: You just see how it goes, yeah. And what do you do if you get stuck?

Laura: Uh, I ask three people and then ask the teacher (discussion between Laura and researcher)

This discussion highlighted that Laura, from the beginning of the school year, could confidently talk about her own thinking and learning, demonstrating metacognitive knowledge. For example, Laura was able to justify why something was deemed easy or difficult, such as saying reading is easy because she understands most words. In addition, Laura began to reflect on strategies used in the face of struggle, by relaying strategies advocated by the class teacher; 'giving it a go' and seeking help from peers before asking the teacher. As such, Laura demonstrated metacognitive knowledge of herself as a learner, as well as strategies available to complete tasks (Flavell, 1979). In describing a specific goal, Laura also demonstrated metacognitive skills that were relatively sophisticated (compared to those offered by her peers), including thinking to the future and planning (Schraw \& Moshman, 1995). This example further interestingly begins to explore Laura's motivation in different subject areas as influencing her performance.

When looking in more depth at Laura's description of her own learning, we found that whilst at times providing in-depth responses, Laura also frequently tended to reflect on the general topic or the output of a task, rather than the process (see Figure 2). For example, in conversation with the researcher about strengths and targets, Laura again focused on topics and subjects;

Laura: My strengths are coding and drawing [...]

Researcher: What is it about these things that you are good at?

Laura: I'm just good at drawing in general

Researcher: Just good in general? What about coding?

Laura: Um, I'm good at making cartoons

Researcher: In coding? That's quite cool. And what about your targets?

Laura: Uh... maths, maths, maths 
Researcher: Maths? What is it in maths that you need to work on a bit?

Laura: Everything (discussion between Laura and researcher)

In this excerpt, Laura again demonstrated metacognitive knowledge of herself as a learner by acknowledging her strengths and limitations (Schraw, 1994). Here, Laura focused on the output as evidence of her skill rather than reflecting on the process, influencing her assessment of her strength in the subject. This focus suggests that rather than self-reflecting on her thinking process throughout the activities, Laura based her self-assessments on her performance - relating the product of her activity to others in the class.

[Figure 2 about here]

\section{'Silly’ Responses}

At the beginning of the school year, Laura was initially engaged in the STAs, as demonstrated by her enthusiasm to discuss her own learning and in excerpts from her learning $\log$ (as shown in Laura' first learning log entry in Figure 3). However, over the course of the year, we found that Laura's talk about her thinking and learning in discussions become more and more facetious as the year progressed, indicating that Laura began to lack motivation and act 'silly' throughout activities. Laura initially indicated that she was lacking motivation for the activities in discussion with the researcher;

Researcher: How do you like answering these - is it fun writing in your diaries?

Laura: No.

Researcher: No? How is it not fun?

Laura: It takes up my good energy of my hand. It's sad (discussion between Laura and researcher)

Laura's lack of motivation for STAs was well captured in a comment in discussion with the researcher whilst completing strengths and targets for her achievement log;

Researcher: Do you think doing things like this helps you to learn? Laura: No, not at all. All we do is sit on chairs and write the boring stuff Researcher: Hmm... what about writing targets for yourself. Do you think that's useful for your learning?

Laura: No (discussion between Laura and researcher)

As the above examples demonstrate, we found that evidence from observations and interviews marked a shift in Laura's engagement with STAs. Indeed, whereas Laura initially engaged with STAs at the beginning of the school year, we found that she quickly became disillusioned with the STAs. Such a finding highlights the interplay between metacognition and motivation in the classroom, suggesting the value of pupils not only having the metacognitive knowledge and skills to participate in STAs, but also the clear value of pupils being motivated to engage with STAs (Zimmerman, 1995).

[Figure 3 about here] 
Despite Laura's discussion of her learning in STAs changing, we found that Laura consistently provided 'appropriate' responses in her written work. The following example demonstrates the dissociation often observed between Laura's written outputs and her verbal engagement with STAs;

Researcher: So, what about next week, what are you going to put lots of effort into?

Laura: Eating

Researcher: What about learning things?

Laura: Oh, uh... [Peer says colouring in] yeah

Researcher: Colouring in? [Nods] Why do you think you need to put lots of effort into colouring in?

Laura: Cause it's fun, and you need to be good at it. If you don't know how to colour in you're going to be never be good at life. You may as well disappear into a rocky mountain forever if you can't colour in properly [giggles]

Researcher: Right, so do you need to get better at colouring in?

Laura: Yeah. If you don't learn how to colour in properly, then you are not going to survive ... you go into a rocky cave, and then just in the last moment, when you are about to go to sleep, a bear comes and eats you and that will be the end to you (discussion between Laura and researcher)

This excerpt is representative of the kind of 'silly' answers that Laura provided in discussion with the researcher or peers. Indeed, several instances of Laura being silly whilst completing STAs were noted. Interestingly, despite Laura being silly throughout the discussion about the sentences for her learning log, in her actual learning log, she wrote 'coding' rather than colouring in (as shown in Figure 4). Laura's written response of coding in addition to her silly response of colouring in stated in discussion, suggests that Laura provided a written response to align with expected written outputs for the STA, despite it not aligning with her verbal reflection.

[Figure 4 about here]

In sum, we found that Laura engaged with STAs by providing relatively detailed responses to prompts, particularly at the beginning of the school year. Such responses demonstrated that in contrast to expectations (e.g., see Veenman et al., 2004), children in the middle primary school years can demonstrate metacognitive knowledge through discussion, as well as demonstrate metacognitive skills through planning (Schraw \& Moshman, 1995; Efklides, 2006). As the year progressed, the routinised nature of STAs in this class influenced Laura's engagement. Laura provided increasingly 'silly' responses in discussion, whilst still producing written responses that aligned with teacher expectations. As such, we found that not only did Laura demonstrate skilfulness, she also demonstrated self-regulated learning by controlling her cognition in accordance with her metacognitive awareness of the task demands, her goals and her motivation for the task (Zimmerman, 1995).

A clear finding of the present study is the crucial interaction between the STA itself and the indicators of metacognition produced by their investigation. Here, the placement of STAs within the classroom routine is identified as something that potentially acts as a barrier to engagement, with Laura quickly becoming bored. This 
highlights how important it is that pedagogic tools can be used flexibly, as well as of maintaining awareness of the appropriateness of pedagogical tools as they are being completed (Leat \& Higgins, 2002). A second clear influence upon Laura's engagement with STAs was the specific content of the STA itself. We found that Laura tended to provide relatively superficial responses to prompts - prompts that were themselves, relatively broad and procedural. More widely, this finding highlights the close association between the tools of measurement of metacognition and the way that metacognition is resultantly judged (Desoete, 2008; Gascoine et al., 2017).

\section{Amy's experience of structured thinking activities}

\section{Limited engagement with structured thinking activities}

Throughout the school year, Amy most often completed no entry in the learning log following the learning chat with Ms. Abbot (as shown in Figure 5). In one observed STA session, field notes revealed Amy's lack of engagement with the learning log;

$2.30 \mathrm{pm}$ Amy is wandering around the class [...]

$2.31 \mathrm{pm}$ Amy crawling on knees. Goes to talk to peer who is looking at a book on the floor. She has a whiteboard on her knee and is reading the story book

2.32pm Peer: Amy, you need to sit at your table [repeats]. Amy still sitting on floor looking at book. Peer comes to sit beside [Amy]. He turns the page on Learning log and begins to write whilst looking over Amy's shoulder at book

2.33 All looking at book together

2.33 Amy looks up at board and has page open on Learning log [...]

2.34 Amy crawls past me and sits directly in front of board with questions.

Stares up at board (observed learning log session)

In discussion with Amy as she sat on the floor, Amy further demonstrated her dislike of the activity;

Researcher: How are you getting on here?

Amy: Good!

Researcher: Good, do you like doing these questions?

Amy: [Shows thumbs down sign and does an exaggerated unhappy face]

Researcher: You don't like it?

Amy: No

Researcher: Why not?

Amy: I don't know, but I don't (discussion between Amy and researcher)

This observed episode and discussion suggested that Amy avoided the learning log and did not enjoy completing the activity. Instead of completing the sentences that Ms.

Abbot had displayed on the board at the front of class, Amy spent a large amount of the task wandering around the class and sitting looking at a book. Therefore, evidence from observations, written excerpts and interviews all suggest that Amy did not fully engage with STAs.

[Figure 5 about here] 


\section{Structured thinking activities and literacy}

Early in the data collection process, a key emerging theme was the repetitive use of 'stock' short answers by Amy in STAs. In written work (Figure 6) and throughout discussions with the teacher and researcher, Amy often provided the same response of 'ICT' (denoting Information and Communication Technologies); regardless of the eliciting question;

Ms. Abbot: What are your strengths, Amy? What do you think you are good at?

Amy: ICT (observed achievement logs discussion)

[Figure 6 about here]

Throughout the course of data collection, Amy's struggle with literacy in comparison to her peers was clear, and we found that this struggle greatly impacted upon Amy's engagement with the STAs. In several observed lessons, Ms. Abbot gathered Amy and a select few other pupils to the front of the class or to a specific table following class discussion to provide additional support. It also became clear over time that Amy's repeated reference to ICT was a strategic negotiation of tasks given her difficulties with literacy. Discussion with the researcher during a learning log session supported this inference;

Researcher: So, you're doing, 'I think I'm showing strength in'

Amy: ICT!

Researcher: ICT?

Amy: Yes

Researcher: Why are you picking ICT?

Amy: Because I love it

Researcher: You love it?

Amy: Yeah

Researcher: And how do you think that you are showing strength in ICT?

Amy: Eh by eh, learning

Researcher: Oh, by learning, and you like learning in ICT?

Amy: Yeah. But, I don't know how to spell learning, so I just write ICT (discussion between Amy and researcher)

Here, discussion with the researcher in the class revealed little evidence of metacognitive knowledge. In contrast to Laura, Amy did not provide a justification for her response that indicated any knowledge about herself as a learner, or the task characteristics, or strategies associated with ICT. Rather, Amy demonstrated a lack of distinction between enjoyment and skill. Furthermore, when asked to elaborate, Amy provided a relatively superficial response of 'learning', which again suggests a lack of metacognitive knowledge of her strengths and weaknesses as a learner (Schraw, 1994; Flavell, 1979). Critically, however, whilst not providing an explicit reflection of the learning process in her STA, Amy did clearly indicate metacognitive knowledge in her response of "I don't know how to write learning". This response suggests that Amy's engagement with the STAs is directly influenced by her awareness of her own cognition (rather than being documented in the STAs themselves). 
At a wider level, the above excerpt strongly suggests that literacy was a barrier to Amy's engagement with the written learning logs. Anticipating that she would be asked to write her response into her learning log, Amy was often reluctant to elaborate or go beyond basic responses in conversation with the teacher. When Amy did not refer to ICT, her response was always short responses of one or two words, as demonstrated in the following excerpt;

Researcher: What kinds of thing have you been learning about in primary 4 ? Amy: BFG

Researcher: Oh, the BFG! Have you been reading the book? [Amy nods] Has it been good?

Amy: [nods]... [starts to write] ... oh I forgot how to spell BFG (discussion between Amy and researcher)

An observed discussion between Ms. Abbot and Amy revealed more insight into the influence of literacy upon Amy's reflections;

Ms. Abbot: What do you want to improve on?... what do you want to get better? Anything at all. What do you think, to make your learning ...? Amy: ICT

Ms. Abbot: Hmm, well I think you're actually quite good at ICT, and that was one of your strengths. What about in the classroom? Something you would like to get better at? What do you think?

Amy: Em... topic

Ms. Abbot: Topic? Tell me how you would get better at topic?

Amy: Hmm...

Ms. Abbot: Maybe working with my team? Maybe that might be your target? Yeah?

Amy: [Pauses and looks at the post-it]

Ms. Abbot: You would write 'target - work with my team'. Will I write that down up here for you? [Ms. Abbot writes on board]

Amy: You're so fast at writing

Ms. Abbot: It's just practice, Amy (observed discussion between Ms. Abbot and Amy)

Here, again, we saw limited evidence of Amy's engagement with the STAs, with reflections being heavily supported by Ms. Abbot. Again, however, this excerpt suggests a clear distinction between Amy's engagement with STA and more subtle indicators of metacognition evidenced through discussion. That is, on the surface, there was limited evidence of Amy reflecting on her own thinking or learning: if Amy was reflecting on her thinking, it might have been expected that she would say that to improve writing was a target. In this instance, Amy provided short and repetitive responses without elaboration, leading ultimately, to Ms. Abbot providing a target for Amy. Rather than providing responses that aligned with her difficulties (an indicator of explicit metacognitive knowledge), Amy instead provided a response indicative of a sophisticated strategy to 'get through' the task set by the class teacher, using a strategy she knew she could rely on (i.e., the spelling of ICT). By contrast, Amy's comment about the ease with which Ms. Abbot wrote provides clear evidence of Amy comparing her writing skills to others. This excerpt, then, again suggests that Amy did have 
awareness of her struggle with literacy, but this was evidenced in more subtle ways than can be captured by (written) STAs.

\section{Discussing learning}

Despite aforementioned examples of inaccurate reflection, we found that non-writing activities provided more evidence of Amy's abilities to elaborate on her thinking and learning. Over the course of the school year, Amy discussed her thinking and learning; particularly when these discussions were not bound by a writing exercise. For example, in a learning chat, Ms. Abbot asked the class what they would like to learn more about next week;

Amy: I want to learn more about our times tables Ms. Abbot: Times tables. [...] what things have we used to learn the times tables this week?

Amy: Em, we have used the triangles and the [inaudible]

Ms. Abbot: What did the triangles help us to remember, which times table? Amy: Three.

Ms. Abbot: Three, and what about the five pence?

Amy: Five

Ms. Abbot: The five. And we made posters, and we did lots of different tricks, didn't we?

Amy: Yep (observed learning chat)

Here, Amy described a taught strategy in discussion with the teacher; a more detailed response than provided in writing. Such a discussion provided evidence that Amy could reflect on strategies associated with thinking and learning to some degree, providing evidence of metacognitive knowledge of strategies (Flavell, 1979; Schraw, 1994). Therefore, we found that discussions between the Ms. Abbot and Amy revealed more about Amy's ability to think about how she has been thinking and learning through STAs than written evidence alone.

In the following extended example, we demonstrate that insight about Amy's thought process in relation to her own work could best be gauged through one-to-one interaction around subjects of interest. From the first observed episode, Amy stated that she enjoyed being creative through dancing, singing and acting, for example describing that she learns best "when I'm standing up and acting things out in drama" (observed learning chat). Towards the end of the school year, pupils reflected on the year's learning in their achievement logs followed by another activity in which pupils could pick cards from a set that prompted them to verbally reflect on their learning. Initially, Amy referred to her 'stock' answer of ICT;

Amy: My goals next year are... more ICT

Researcher: More ICT? If you didn't need to write it and we just talked about it, what kinds of thing would you like to learn? We don't need to write it, we can just chat about it

Amy: Hmm... ICT... [gets distracted by toy at the table]

Researcher: So, what about next year, what do you think your goals are?

Amy: Hmm, eh, eh, eh, ICT [writes] (discussion between Amy and researcher) 
Throughout this conversation, Amy was reluctant to respond anything other than ICT, writing this as a response to several different questions. At a point in the discussion, Amy described that when she leaves school, she would like to be "... a dancer or singer, or an accordionist". Amy then went on to use movements to describe her responses; "let's see if I can spell BFG with my arms [makes movements with arms]". As such, the researcher shifted the exercise away from written responses;

Researcher: What if you were to show me with movements, what your favourite moment was this year? Can you act it out?

Amy: [Pretends to type on computer]

Researcher: Oh, you're looking happy there, typing away on your computer Amy: I'm actually doing a PowerPoint [...]

Researcher: Oh, is it a PowerPoint all about food? [nods] What are you putting on it?

Amy: Pizza, donuts

Researcher: They're quite tricky things to do on the PowerPoint as well, are you putting pictures on there?

Amy: [Nods and continues to act] You em, go onto google, type in what you want, I type in cake and then I go down and click on a picture. Then I click on the picture with this bit of the mouse [points to imaginary mouse on table] on this bit [points to right], then you copy the image. Then you go onto PowerPoint, and go onto the big picture, you click on it, and then there's the image! (discussion between Amy and researcher)

In this one-to-one interaction, Amy provided a more in-depth description of the specific actions taken during the PowerPoint exercise than she had been observed to complete previously in any written or verbal reflection throughout the school year. Amy's very detailed description of how to insert a picture into a PowerPoint presentation during this session revealed Amy's ability to articulate how to perform activities. This finding demonstrates that whilst Amy tended to provide relatively superficial and repetitive responses, when the conditions were right, she could reflect on the process of thinking and learning, demonstrating metacognitive knowledge of what and how' in relation to strategies (Schraw \& Moshman, 1995).

In sum, we found that Amy was reluctant to reflect on thinking or learning in written STAs, most commonly referring to 'stock' responses. Through one-to-one interaction in activities of interest, Amy provided more detail about her thinking processes than in any written or oral STA. Clearly, this finding highlights the importance of tools being pedagogically appropriate. Whilst evidence supports the specific value of pedagogies that support deep, reflective talk between teacher and pupils (Leat \& Higgins, 2002), we found that this talk was limited by the anticipation that there would be a written exercise to follow. As such, the reliance upon written exercises was a barrier to engagement with the particular STAs used routinely in Forestview Primary School. Of course, our limited evidence does not necessarily translate to a lack of metacognition per se, but rather a restricted capacity for Amy to express her metacognitive knowledge or skills. Amy may not have been able to express herself in writing, and may not have developed the language of thinking and learning required to express herself in the ways that these STAs demand. More broadly, this finding again highlights that the evidence of metacognition is ultimately bound within the tool of measurement (Gascoine et al., 2017). 


\section{Drawing together Laura and Amy's experiences of structured thinking activities}

Throughout data collection, clear differences were observed between the ways that Laura and Amy experienced STAs. We found more evidence of Laura explicitly thinking about her own thinking and learning than Amy, both in written activities and in the depth of responses provided in learning chats. To Amy, difficulties with literacy and the predominance of written activities through the 'learning log' were barriers to engagement with STAs and led to reliance upon 'stock' responses. Nevertheless, discussion provided a route to understand more subtle evidence of Amy thinking about her thinking, influencing her engagement with the STAs themselves.

Despite differences, a similarity that we found between Laura and Amy is that both pupils appeared to often provide responses in STAs that aligned with those expected by the teacher, rather than providing necessarily 'accurate' reflections of own skills. Throughout the year, Laura displayed signs of being 'good' at STAs by reflecting on her own thinking and learning, and this was clearly reflected in the teachers' perspectives from the beginning of the year and throughout. However, through observation and discussions over time, it became clear that Laura knew what to do to 'tick the boxes' and produce the desired outputs, without necessarily engaging in meaningful thinking about her own thinking or the learning process. Similarly, although verbal activities provided more evidence of Amy's abilities to elaborate on her thinking and learning than writing activities, Amy did tend to rely on the same responses, elaborating only when explicitly encouraged to by Ms. Abbot (or the researcher). As such, we found that whilst pupils differed in their metacognitive knowledge (observed through investigations of their engagement with the STA), neither Amy nor Laura particularly engaged with STAs for their intended purpose (as a platform to think about and manage their own thinking or learning).

A key finding in the present research is that that both Laura and Amy strategically negotiated their way through the STAs in accordance with their assessments of the activities themselves - suggesting they engaged with activities in ways more similar than it appeared in written form. In a sense, both Amy and Laura knew what to do to 'get through' the STAs in some way, whether it was Amy making the task as simple as possible to avoid having to write more than 'ICT'; or whether it was Laura being silly with friends before writing a response in the learning log that fitted with the teacher's expectations. As such, the pupils were more similar in their strategic approach to completing STAs than it appeared from written outputs alone. That is, both pupils regulated their cognition in line with their goals (Zimmerman, 2005). In sum, both Amy and Laura, rather than engaging with STAs for their intended purpose (as metacognitive tools), instead both negotiated the 'game' of STAs, with Laura perhaps being more efficient at playing this game than Amy.

In exploring the potential reasons for pupils' superficial metacognitive responses in the STAs investigated, it is pertinent to consider the interaction between response and pedagogy. Indeed, we found that both pupils provided relatively 'superficial' reflections of their own thinking and learning, a finding that parallels previous research using concept maps to explore the increasing 'sophistication' of pupils' metacognitive reflections as they progress from primary to secondary school (Ritchhart et al., 2009). Our finding of the relatively superficial responses provided by primary four pupils in 
the current study is also indicative of reflections of relatively 'surface' rather than 'deep' learning, a focus upon quality of learning (Biggs \& Collis, 1982; Dart et al., 1999), suggesting that this distinction can also be made in the metacognitive domain.

This finding raises an interesting point in consideration of the content of the STAs and their influence on pupil reflections. Whilst we observed fairly 'surface' reflections, it is arguably inevitable given the relative 'surface' questions being asked in the STAs. This finding speaks to the interaction between pedagogy and indicators of metacognition, reinforcing the idea that 'how you test is what you get' (Desoete, 2008, p204).

\section{General Discussion}

In the present study, we aimed to explore the use of STAs in relation to supporting pupils' developing metacognition. By focusing our investigation specifically on Laura and Amy, we used observations and interviews to develop rich understanding about the ways individual pupils used STAs to think about and manage their own thinking. We found clear differences in the ways both pupils engaged with STAs, with Laura providing clear responses indicative of metacognitive knowledge in written STAs, and Amy providing little (if any) response to STA prompts. Critically, extended investigation of STAs revealed similarities between pupils beyond those revealed through written responses alone. More specifically, we argue that both Laura and Amy used their metacognitive knowledge of their own skills and task requirements to strategically negotiate the task (Flavell, 1979); Amy by repeatedly referring to 'stock' responses that she knew she could spell, and Laura by writing responses that fitted what Ms. Abbot expected, whilst entailing minimum effort. As such, we found that neither Amy or Laura took full advantage of the intended use of STAs as metacognitive tools, however in negotiating the task, both exhibited regulatory skills indicative of metacognition (by controlling their behaviour based on strategic assessments of task requirements (Schraw \& Moshman, 1995; Veenman \& Spaans, 2005).

Our finding that both Amy and Laura strategically negotiated their engagement with STAs in line with their assessments of the demands of the activities themselves emphasises a focus upon pupils 'getting through' the STAs rather than using them as tools to assist metacognition. We are caused to question what this finding means for the use of STAs to encourage metacognition within the classroom. One interpretation of the current findings is that 'success' in STAs relies upon pupils indeed learning to act the correct way; to produce the right outputs that align with what the teacher expects of them. With such a position, it might be argued that through investigating STAs, we are in fact gauging pupils' abilities to play the 'game of school' (and the game of appearing metacognitive) rather than gauging pupils' actual metacognition. Indeed, such a finding may not be unique to STAs, with a view of teaching as transferring notions of 'correctness' to learners being a key aspect of traditional 'direct' modes of teaching (Skinner, 2010).

Critically, we do not interpret our findings as being evidence to support the diminishing of the purpose of STAs within the classroom. In fact, we found that through negotiating STAs, pupils demonstrated strategies that indicated that they had assessed the requirements of the activities and acted in line with their own perceived skills. As such, the present findings demonstrate that both pupils acted on assessments of their own metacognitive knowledge of persons and tasks (Flavell, 1979); they demonstrated metacognition. 
For both Laura and Amy, the ability to gauge pupils' metacognitive knowledge and skills was bound heavily by the tool investigated. Learning logs, achievement logs and associated discussions are prominent pedagogical tools in Scottish classrooms, however they are by no means the only method for encouraging pupils to think about their own thinking and learning (for an overview of the diversity of approaches utilised in schools, see Higgins et al., 2007). Earlier, we considered one such approach, Pupil Views Templates (Wall, 2008; Wall et al., 2012). PVTs have been powerful for demonstrating the nuance of children's developing awareness of their own thinking and learning, revealing that children can indeed engage in strategic and reflective thinking from the early primary school years (Wall, 2008). In the present study, rather than seeking to intervene (or change pedagogy in any way), we sought to explore one existing pedagogical tool for metacognition and explore pupils' engagement through rich description that is often missing from psychological research. Like previous research (Wall, 2008; Whitebread et al., 2009), we found that children can indeed think about and manage their own thinking by the middle primary school years, however perhaps in somewhat different ways than might be expected based on analysis of written evidence alone.

In relation to understanding developing metacognition, the present findings provide evidence to suggest that in primary 4, whilst pupils have developed a certain implicit sense of their own cognition, these skills have not necessarily become explicit or stateable to fully engage with the explicit requirements of STAs. This finding is clearly supported by the finding that despite limited engagement with STAs, discussions with Amy revealed that she did have a clear sense of her own thinking (including difficulties with literacy), which impacted upon engagement with the STAs themselves. Indeed, the explicit, self-reflective nature of STAs may necessitate a level of conscious, stateable metacognitive knowledge, "stable, familiar constant, established long-term knowledge which involves self-knowledge, self-awareness and a sensitivity to and evaluation of this knowledge" (Tarricone, 2011, p156) that has not yet developed sufficiently to engage in STA activities (Kuhn, 2000). Our findings, therefore, revealed that students clearly thought about and managed their own thinking through STAs, but they had not necessarily developed sufficient understanding of their own thinking process to engage in STA activities in the way intended.

In understanding the development of metacognition, it is important to acknowledge that STAs do not measure all aspects of metacognition and are only one pedagogic tool available for teachers. In the STAs investigated presently, students were primarily asked to reflect on their thinking and learning from the week, term or year, as well as to think ahead by planning and setting goals for the coming week, term or year. As such, STAs elicit students' explicit 'statable' metacognitive knowledge (Tarricone, 2011). What they did not capture, is the more 'on-line' metacognitive experiences that relate to monitoring and control during tasks (Efklides, 2006). STAs require more from students in terms of metacognition and wider self-regulation. They rely on memory of the past, and projection into the future. They also require a suspension of current goals, in favour of the goals of the past, or goals for the future. Thus, while our findings clearly highlight that pupils can indeed think about and manage their own thinking, this understanding of pupil development is necessarily bound within the measures and tools utilised (Gascoine et al., 2017; Wall, 2008; Desoete, 2008). 
Going beyond the examination of metacognition alone, clearly an examination of the wider framework of self-regulation theory is appropriate in our present interpretation to understand the critical way that pupils' motivations influence metacognition and strategic behaviour throughout STAs. Through the inclusion of motivation in a model of self-regulation, we are compelled to look at learning from a more social cognitive viewpoint, allowing us to consider the varying influences of the social world (Zimmerman, 1995). The relationship between metacognition and motivation was clear throughout our findings, highlighting that pupils must be motivated to take part in STAs, and must see them as supportive of learning. Critically, therefore, we found that both Laura and Amy demonstrated self-regulation (Zimmerman, 2005), by controlling their cognition in line with their own goals. In STAs, however, we found that pupils' goals (i.e., to 'get through' the task) did not necessarily align with the intended goals of the STAs (to encourage metacognition by planning and reflecting on thinking).

It is possible that an alignment between teachers and pupils' goals in STAs necessitates some level of cognitive or self-regulatory maturity beyond the pupils included in the present study, again aligning with an understanding of metacognition as a suite of skills that become more 'fine-tuned' throughout childhood (Roebers, 2014). It is critical to also bear in mind, however, that Ms. Abbot's primary four class included in the present study were being introduced to learning chats and learning logs for the first time as the research study began. Furthermore, the STAs investigated in the present study form only part of the pedagogical tools that teachers employ to support learning to think and learning to learn (Baumfield, Hall, Higgins \& Wall, 2009; Higgins et al., 2007). Ultimately, our findings emphasise that facilitating metacognition through the use of diverse STAs is not a simple task for teachers, and requires an extended commitment from teachers and school leaders rather than an expected 'quick fix' (Baumfield et al., 2009).

In the present study, our understanding of pupils' metacognition is necessarily restricted by the specific content of the STAs themselves. In this classroom, learning $\operatorname{logs}$ and achievement logs were STAs that were used as catalytic tools for metacognition; "Tools, as technologies have been designed to make a particular activity different: faster, slower, richer, more focused, more efficient, more sustained" (Baumfield et al., 2009, p424). With the use of STAs therefore, the teacher is enabled to explore a greater depth of meaning in relation to pupils' learning - STAs are not just an output, but a vital part of the metacognitive process itself. The limited degree that the pupils engaged with the STAs themselves means that the catalytic nature of STAs is clearly of interest in the present study. For example, the fact tools such as STAs produce feedback (Baumfield et al., 2009), raises questions about the extent to which the STAs explored in the present study might be considered catalytic of further pedagogic practices for metacognition.

Most importantly, then, consideration of the (conflicting) goals of STAs within the classroom causes us to consider the critical social interactions that are inherent to the use of STAs in classrooms. Indeed, the clear influence of social dynamics that encompass STAs is demonstrated by our finding that written evidence is only one aspect of STAs, with deeper insight being produced when examining the socio-cultural dimensions of the classroom such as the talk between pupils, peers and the teacher (Zimmerman, 1995). A focus on the role of social interactions is important because it 
changes the way we look at STAs. Rather than simply providing a platform for pupils to document their metacognitive processes (something to 'get through' or get right'),

STAs are a set of activities that (when used within the social space of the classroom) act as a catalyst for talking about, and thinking about, thinking (Baumfield et al., 2009).

In sum, our findings add weight to the growing view that "how you test is what you get" (Desoete, 2008, p204). Importantly, the present findings extend previous research by highlighting a distinction between implicit, online experiences of cognition (as revealed through observation of STA activities) and more explicit, 'statable' knowledge of the thinking and learning that the STAs require (as evidenced by written evidence). In classrooms, both implicit and explicit signs of meta-cognitive engagement are present, and any conclusions will depend on which is measured. Whilst our focus in the present paper is on pupil experiences rather than pedagogy per se, findings were inherently reliant on the content and use of the STAs investigated. As such, our findings have implications for understanding how to facilitate pupils' understandings of their own thinking and learning. In particular, it is critical that STAs are diverse (to avoid boredom); it is important that STAs are appropriate in relation to other developing skills (such as literacy or vocabulary); and it is necessary that STAs are embedded within (and instrumental for) a wider pedagogy (of dialogue, feedback, planning and instruction) (Baumfield, 2006; Baumfield et al., 2009). Given the rich interplay between pedagogy and pupil engagement, we also need to look more at the social interactions that encapsulate learning logs as a particular form of STA. Clearly, one such area to investigate is the critical role of the teacher in facilitating and/or inhibiting metacognition using the STAs, and the resultant impact on pupil engagement, motivation and metacognition. 


\section{References}

Adey, P.S., \& Shayer, M. (1990) Accelerating the development of formal thinking in middle and high-school students. Journal of Research in Science Teaching 27: 267-285. DOI: 10.1002/tea.3660270309

Adey, P.S., Shayer, M., \& Yates, C. (1995) Thinking Science: The Curriculum Materials of the CASE Project. London: Thomas Nelson and Sons.

Altheide, D.L. \& Johnson, J.M. (1998). Criteria for Assessing Interpretive Validity in Qualitative Research. In Denzin, N.K. and Lincoln, Y.S. (Eds). Collecting and Interpreting Qualitative Materials (pp 283-312). London: Sage

Armbruster, B. B., Echols, C. H., \& Brown, A. L. (1982). The role of metacognition in reading to learn: a developmental perspective. The Volta Review, 84, 45-56.

Audet, R.H., Hickman, P. \& Dobrynina, G. (1996). Learning logs: a classroom practice for enhancing scientific sense making. Journal of Research in Science Teaching, 33(2), 205-222. DOI: https://doi.org/10.1002/(SICI)10982736(199602)33:2\%3C205::AID-TEA5\%3E3.0.CO;2-Y.

Barclay, J. (1996). Learning from experience with learning logs. Journal of Management Development, 15(6), 28-43. DOI:10.1108/02621719610120129

Bartsch, K., Horvath, K. \& Estes, D. (2003). Young children's talk about learning events. Cognitive Development, 18(2), 177-193. DOI: 0.1016/S08852014(03)00019-4

Baumfield, V. (2006) Tools for pedagogical inquiry: the impact of teaching thinking skills on teachers, Oxford Review of Education, 32:2, 185-196, DOI: 10.1080/03054980600645362

Baumfield, V.M., Hall, E., Higgins, S. \& Wall, K. (2009) Catalytic tools: understanding the interaction of enquiry and feedback in teachers' learning, European Journal of Teacher Education, 32:4, 423-435, DOI: 10.1080/02619760903005815

Biggs, J. B., \& Collis, K. F. (1982). Evaluating the quality of learning: The SOLO Taxonomy (Structure of the Observed Learning Outcome). London: Academic Press.

Bryman, A. (2012). Social Research Methods. Oxford: Oxford university press.

Charmaz, K. (2000). Grounded Theory: Objectivist and Constructivist Methods. In Denzin, N. and Lincoln, Y.S. (Eds). Handbook of Qualitative Research, Second edition (pp509-535). London: Sage

Craft, A., Cremin, T., Hay, P. \& Clack, J. (2014) Creative primary schools: developing and maintaining pedagogy for creativity, Ethnography and Education, 9(1), 1634. DOI: 10.1080/17457823.2013.828474

Dart, B., Burnett, P., Boulton-Lewis, G., Campbell, J., Smith, D. \& McCrindle, A. (1999). Classroom learning environments and students' approaches to learning. Learning environments research, 2(2), 137-156. DOI: 10.1023/A:1009966107233

Desoete, A. (2008). Multi-method assessment of metacognitive skills in elementary school children: how you test is what you get. Metacognition Learning, 3: 189206. DOI: 10.1007/s11409-008-9026-0

Destan, N., Hembacher, E., Ghetti, S. \& Roebers, C. M. (2014). Early metacognitive abilities: The interplay of monitoring and control processes in 5-to 7-year-old children. Journal of Experimental Child Psychology, 126, 213-228. DOI: 10.1016/j.jecp.2014.04.001

Dignath, C., Buettner, G. \& Langfeldt, H. P. (2008). How can primary school students learn self-regulated learning strategies most effectively? A meta-analysis on 
self-regulation training programmes. Educational Research Review, 3(2), 101129. DOI:10.1016/j.edurev.2008.02.003

Education Scotland (2018). What is Curriculum for Excellence? Retrieved from: https://education.gov.scot/scottish-education-system/policy-for-scottisheducation/policy-drivers/cfe-(building-from-the-statement-appendix-incl-btc15)/What\%20is\%20Curriculum\%20for\%20Excellence?

Efklides, A. (2006). Metacognition and affect: What can metacognitive experiences tell us about the learning process? Educational Research Review, 1: 3-14. DOI: 10.1016/j.edurev.2005.11.001.

Feuerstein R, R., Hoffman, M.B., \& Miller, R. (1980) Instrumental Enrichment: an Intervention Programme for Cognitive Modifiability. Baltimore: University Park Press.

Fisher, R. (2007) Dialogic teaching: developing thinking and metacognition through philosophical discussion, Early Child Development and Care, 177:6-7, 615-631, DOI: $10.1080 / 03004430701378985$

Flavell, J. H. (1979). Metacognition and cognitive monitoring: A new area of cognitivedevelopmental inquiry. American Psychologist, 34(10), 906. DOI: 10.1037/0003-066X.34.10.906

Flavell, J.H., Friedrichs, A.G. \& Hoyt, J.D. (1970). Developmental changes in memorization processes. Cognitive Psychology, 1, 324-340. DOI: 10.1016/00100285(70)90019-8

Fontana, A. \& Frey, J. H. (1998). Interviewing: The Art of Science. In Denzin, N.K. and Lincoln, Y.S. (Eds). Collecting and Interpreting Qualitative Materials (pp 4778). London: Sage

Gascoine, L., Higgins, S. \& Wall, K. (2017). The assessment of metacognition in children aged 4-16 years: a systematic review. Review of Education, 5: 3-57. DOI:10.1002/rev3.3077

Geertz, C. (1973). Thick description: Toward an interpretive theory of culture. In the Cultural Geography Reader (pp. 311-323). Routledge.

Hammersley, M. (2006) Ethnography: problems and prospects, Ethnography and Education, 1(1), 3-14. DOI: 10.1080/17457820500512697

Hattie, J., Biggs, J. \& Purdie, N. (1996). Effects of learning skills interventions on student learning: A meta-analysis. Review of Educational Research, 66(2), 99136. DOI: https://doi.org/10.3102/00346543066002099

Higgins, S.E., Baumfield, V.M., Lin, M., Moseley, D., Butterworth, M., Downey, G., Gregson, M., Oberski, I., Rochett, M. \& Thacker, D. (2004). Thinking skills approaches to effective teaching and learning. London: EPPI-Centre, Social Science Research Unit, Institute of Education.

Higgins, S., Hall., E., Baumfield., V. \& Moseley., D. (2005). A meta-analysis of the impact of the implementation of thinking skills approaches on pupils. London: EPPI-Centre, Social Science Research Unit, Institute of Education, University of London.

Higgins, S., Katsipataki, M., Villanueva-Aguilera, A.B., Coleman, R., Henderson, P., Major, L.E., Coe, R. \& Mason, D. (2016). The Sutton Trust-Education Endowment Foundation Teaching and Learning Toolkit. Manual. Education Endowment Foundation, London.

Higgins, S.,Wall, K., Baumfield, V., Hall, E., Leat, D., Moseley, D., et al. (2007). Learning to Learn in Schools Phase 3 Evaluation: Final Report. London: Campaign for Learning. 
Jeffrey, B. (2008). Characteristic Social Settings as the Basis for Qualitative Research in Ethnography. In Walford, G. (Eds). How to do Educational Ethnography (115-139). London: The Tufnell Press.

Jeffrey, B. \& Troman, G. (2004). Time for ethnography. British Educational Research Journal, 30(4), 535-548. DOI: 10.1080/0141192042000237220

Kuhn, D. (2000). Metacognitive development. Current Directions in Psychological Science, 9(5), 178-181. DOI: 10.1111/1467-8721.00088

Leat, D. \& Higgins, S. (2002). The role of powerful pedagogical strategies in curriculum development. The Curriculum Journal, 13:1, 71-85, DOI: 10.1080/09585170110115286

Lipman M., Sharp, A. \& Oscanyan F (1980) Philosophy in the Classroom. Princeton: Temple University Press.

Mallozzi, F. N. \& Heilbronner, N. (2013). The effects of using interactive student notebooks and specific written feedback on seventh grade students' science process skills. Electronic Journal of Science Education, 17(3), 1-24.

Misailidi, P. (2010). Children's Metacognition and Theory of Mind: Bridging the Gap. In Efklides, A.\& Misailidi, P. (Eds). Trends and Prospects in Metacognition Research (p279-293). London: Springer

Moon, J. (2002). Learning logs: A Handbook for Academics, Students and Professional Development. London: Kogan Page Limited

Nückles, M., Hübner, S., \& Renkl, A. (2009). Enhancing self-regulated learning by writing learning protocols. Learning and Instruction, 19(3), 259-271. DOI: 10.1016/j.learninstruc.2008.05.002

Paris, S. \& Paris, A. (2001). Classroom applications of research on self-regulated learning. Educational Psychologist, 36(2), 89-101. DOI: 10.1207/S15326985EP3602_4

Perry, N. E. (1998). Young children's self-regulated learning and contexts that support it. Journal of Educational Psychology, 90(4), 715. DOI: 10.1037/00220663.90.4.715

Perry, N., VandeKamp, K., Mercy, L. \& Nordby, C. (2002). Investigating teacherstudent interactions that foster self-regulated learning. Educational Psychologist, 37(1), 5-15. doi: 10.1207/S15326985EP3701_2

Ritchhart, R., Turner, T. \& Hadar, L. (2009). Uncovering students' thinking about thinking using concept maps. Metacognition and Learning, 4(2), 145-159. DOI: 10.1007/s11409-009-9040-x

Robson, C. (2011). Real World Research (Third Editon). West Sussex: Wiley

Robson, S. (2016a) Self-regulation, metacognition and child- and adult-initiated activity: does it matter who initiates the task? Early Child Development and Care, 186:5, 764-784, DOI: 10.1080/03004430.2015.1057581

Robson, S. (2016b). Self-regulation and metacognition in young children: Does it matter if adults are present or not? British Educational Research Journal, 42(2), 185-206. DOI: https://doi.org/10.1002/berj.3205

Roebers, C.M. (2014). Children's Deliberate Memory Development: The Contribution of Strategies and Metacognitive Processes. In Bauer, P.J. \& Fivush, R. (Eds). The Wiley Handbook on the Development of Children's Memory (pp 865-894). Oxford: Wiley-Blackwell.

Schraw, G. (1994). The effect of metacognitive knowledge on local and global monitoring. Contemporary Educational Psychology, 19(2), 143-154. DOI: 10.1006/ceps.1994.1013 
Schraw, G. \& Moshman, D. (1995). Metacognitive theories. Educational Psychology Review, 7(4), 351-371.

Scottish Government (2009). Curriculum for Excellence Building the Curriculum 4: Skills for Learning, Skills for Life and Skills for Work. Edinburgh: Scottish Government.

Skavhaug, I. M., Wilding, E. L. \& Donaldson, D. I. (2010). Judgments of learning do not reduce to memory encoding operations: Event-related potential evidence for distinct metacognitive processes. Brain research, 1318, 87-95. DOI: 10.1016/j.brainres.2009.11.047

Skinner, D. (2010). Effective Teaching and Learning in Practice. London: Bloomsbury Publishing.

Smith, K.S., Rook, J.E. \& Smith, T.W. (2007). Increasing student engagement using effective and metacognitive writing strategies in content areas. Preventing School Failure: Alternative Education for Children and Youth, 51(3), 43-48. DOI:10.3200/PSFL.51.3.43-48

Strauss, A. L. \& Corbin, J. (1991). Basics of Qualitative Research: Grounded Theory Procedures and Techniques (3rd ed). London: Sage Publications

Swanson, L. (1990). Influence of metacognitive knowledge and aptitude on problem solving. Journal of Educational Psychology, 82(2): 306-314. DOI: 10.1037/0022-0663.82.2.306

Tarricone, P. (2011). The Taxonomy of Metacognition. East Sussex: Psychology Press

Veenman, M. V. J. \& Spaans, M. A. (2005). Relation between intellectual and metacognitive skills: Age and task difference. Learning and Individual Differences, 15, 159-176. DOI: 10.1016/j.lindif.2004.12.001

Veenman, M. V., Van Hout-Wolters, B. H. \& Afflerbach, P. (2006). Metacognition and learning: conceptual and methodological considerations. Metacognition Learning, 1: 3-14. DOI: 10.1007/s11409-006-6893-0

Veenman, M. V., Wilhelm, P. \& Beishuizen, J. J. (2004). The relation between intellectual and metacognitive skills from a developmental perspective. Learning and instruction, 14(1), 89-109. DOI: 10.1016/j.learninstruc.2003.10.004

Walford, G. (2009). The practice of writing ethnographic fieldnotes, Ethnography and Education, 4(2), 117-130. DOI: 10.1080/17457820902972713

Wall, K. (2008). Understanding metacognition through the use of pupil views templates: Pupil views of Learning to Learn. Thinking skills and creativity, 3(1), 23-33. DOI: $10.1016 /$ j.tsc.2008.03.004

Wall, K. \& Higgins, S. (2006). Facilitating metacognitive talk: a research and learning tool. International Journal of Research and Method in Education, 29:1, 39-53, DOI: 10.1080/01406720500537353

Wall, K., Higgins, S., Remedios, R., Rafferty, V. \& Tiplady, L. (2012). Comparing Analysis Frames for Visual Data Sets: Using Pupil Views Templates to Explore Perspectives of Learning. Journal of Mixed Methods Research, 7(1) 22-42. DOI: $10.1177 / 1558689812450211$

Whitebread, D. \& Basilio, M. (2012) The emergence and early development of selfregulation in young children. Profesorado: Journal of Curriculum and Teacher Education, 16(1), 15-34.

Whitebread, D., Coltman, P., Pasternak, D. P., Sangster, C., Grau, V., Bingham, S., Almeqdad, Q. \& Demetriou, D. (2009). The development of two observational tools for assessing metacognition and self-regulated learning in young children. Metacognition and Learning, 4(1), 63-85. DOI: 10.1007/s11409-008-9033-1

Yin, R. L. (2009). Case Study Research: Design and Methods. London: Sage 
Zimmerman, B. (1990). Self-regulated learning and academic achievement: an overview. Educational Psychologist, 25(1), 3-17. DOI: https://doi.org/10.1207/s15326985ep2501_2

Zimmerman, B. (1995). Self-regulation involves more than metacognition: a social cognitive perspective. Educational Psychologist, 30(4), 217-221. DOI: http://psycnet.apa.org/doi/10.1207/s15326985ep3004_8

Zimmerman, B.J. (2005). Self-regulation involves more than metacognition: a social cognitive perspective. Educational Psychologist, 30(4), 217-221. DOI: $10.1207 / \mathrm{s} 15326985 \mathrm{ep} 3004 \_8$

Zohar, A. and Peled, B. (2008). The effects of explicit teaching of metastrategic knowledge on low-and high-achieving students. Learning and Instruction, 18(4), 337-353. DOI: 10.1016/j.learninstruc.2007.07.001 
Figure 1. Example target evaluation from achievement log at Forestview Primary School

Figure 2. Excerpts demonstrating Laura's focus on topics/subjects in achievement log from term 2 (above) and learning log (below)

Figure 3. Laura's first entry in her learning log, demonstrating Laura's initial motivation to engage with STAs

Figure 4. Learning log entry made by Laura, demonstrating written responses that aligned with teacher expectations. This written response can be contrasted to verbal response.

Figure 5. Excerpts from Amy's learning log showing no or little written entries on four occasions

Figure 6. Examples demonstrating Amy's repetitive use of ICT in responses in learning logs on two occasions 